\title{
A INFLUÊNCIA DA ILUMINAÇÃO PÚBLICA NA SEGURANÇA URBANA NOTURNA
}

\section{THE INFLUENCE OF STREET LIGHTING ON URBAN NIGHT SAFETY}

\author{
Felipe Buller Bertuzzi
}

\section{Resumo}

A iluminação está sendo cada vez mais compreendida como um fator fundamental para assegurar a sensação de segurança aos indivíduos. Em diversos estudos científicos predominam relatos contínuos acerca da influência da iluminação como destaque de percursos e fortalecedor da sensação de segurança. Para tanto, o presente artigo visou discutir a aplicabilidade da iluminação pública no ambiente noturno e os seus impactos com relação à segurança. Buscou-se compreender a inserção da iluminação pública nas cidades e, a partir de estudos de caso e de revisões de literatura, relacioná-la a princípios norteadores de Prevenção de Crimes por meio de Projetos (CPTED): vigilância natural, territorialidade, controle natural de acessos, manutenção, uso e atividade. Dentre as discussões, verificou-se fortemente a relação do espaço urbano com o princípio de vigilância natural, exacerbado positivamente em áreas centrais e precário em bairros mais distantes, devido a falta de locais iluminados.

\begin{abstract}
Lighting is increasingly being understood as a key factor in ensuring a sense of security for individuals. In several scientific studies, continuous reports prevail about the influence of lighting as a highlight of paths and strengthening the sense of security. Therefore, this article aimed to discuss the applicability of public lighting at night and its impacts on safety. We sought to understand the insertion of public lighting in cities and, from case studies and literature reviews, relate it to guiding principles of Crime Prevention through Projects (CPTED): natural surveillance, territoriality, natural control access, maintenance, use and activity. Among the discussions, the relationship between urban space and the principle of natural surveillance was strongly verified, positively exacerbated in central areas and precarious in more distant neighborhoods, due to the lack of illuminated places.
\end{abstract}

Keywords: Urban space. Artificial lighting. Public security.

Palavras-chave: Espaço urbano. Iluminação Artificial. Segurança Pública. 


\section{IntRodução}

Em um estudo realizado por Bargos e Matias (2011), a área verde urbana foi conceituada como um espaço composto por no mínimo $70 \%$ de área permeável e que possibilita locais para o lazer, funções estéticas e ecológicas. A fim de investigar esses locais, muitos estudos têm surgido com foco na percepção do usuário frente aos espaços livres.

Ribeiro (2009) aponta que, apesar dos benefícios à saúde dos indivíduos provenientes da arborização na área urbana, é necessário levar em consideração a projeção de outros fatores no ambiente. Um deles, na visão de Mascaró (2006), é a relação da iluminação noturna com a segurança do usuário, a fim de facilitar o trajeto no ambiente.

Com base nessa problemática, o estudo desenvolvido por Reckziegel (2009) buscou investigar a percepção dos usuários em relação aos locais que oferecem lazer noturno. Mesmo sendo voltadas a estabelecimentos comerciais, as considerações finais do trabalho foram positivas, as quais aliaram a sensação de segurança à iluminação pública.

Para Góis (2011), a iluminação artificial tem o poder de orientar a dinâmica urbana durante o período da noite, interpretando a paisagem a partir da disposição da fonte de luz e, consequentemente, de sua iluminância. Mesmo assim, essa metamorfose ocasionada pela variação de turnos não implica a alteração das características urbanas já consagradas, porém incorpora uma nova visão de cidade a partir de atributos que só podem ser vistos à noite, como: vigilância natural, territorialidade, controle natural de acessos, manutenção, uso e atividade, despertando novas percepções dos usuários (SANTOS, 2008). Da mesma forma, Fernandes (2016) defende a iluminação noturna como um fator primordial à vivificação do espaço público noturno.

Mais do que a quantidade de luz que se coloca no espaço público é a qualidade dessa luz que permite alcançar objetivos como a segurança e o conforto, que por sua vez estão na base da vivificação dos espaços públicos. A luz pode dar sentido a um lugar, dar-lhe um novo va- lor de uso. A iluminação pública deve ser um espaço de criação e ajuste da cidade que não dorme (FERNANDES, 2016, p. 8)

Ao levar em consideração a qualidade do espaço público, verifica-se a presença de diferentes tipos de usuários em ambientes noturnos como consequência da diversificação de atividades ali presentes, a fim de aumentar as interações sociais entre os indivíduos (JACOBS, 2000). Assim, vê-se necessário avaliar essa interação entre o usuário e o ambiente construído, a fim de compreender as respectivas percepções ao averiguar a infraestrutura local (MOSER, 1998).

No entanto, para que as interações aconteçam no meio urbano, é necessário que a população se sinta segura nos trajetos que realiza. Os espaços públicos noturnos, quando mal planejados, intensificam a violência e dificultam a permanência de pessoas devido à falta de sensação de segurança (GÄRTNER, 2008). Com base nisso, o presente artigo visa discutir a aplicabilidade da iluminação pública com base nas necessidades do usuário frente ao espaço urbano noturno. Objetiva-se compreender a inserção da iluminação pública na cidade ao relacioná-la a princípios norteadores de Prevenção de Crimes por meio de Projetos (CPTED).

\section{A Iluminação Pública e o Espaço Noturno}

No século XVIII, a vida noturna não tinha predominância no Brasil. A vivificação urbana ocorria ao longo do dia, já que à noite a reunião de pessoas ocorria individualmente em suas respectivas casas, iluminadas por lamparinas e velas. Um dos motivos pelo qual as pessoas se recolhiam era consequente da insegurança que os assolava (VIEIRA e LIBERATTI, 2018). Posteriormente, no final do século $X X$, essa condição foi sendo alterada gradativamente. Por mais que a segurança continuasse sendo um problema a ser enfrentado pela população, a vida urbana noturna passou a ser mais frequente no dia a dia dos indivíduos. Em um estudo desenvolvido por Constantino (1994), a cidade gaúcha de Porto Alegre foi estudada com o intuito de compreender esse acréscimo de atividades no terceiro turno do dia. Para a autora, o que antes predominava ao longo do dia, hoje protagoniza no período noturno, a 
partir dos divertimentos públicos bastante aceitos pela população (CONSTANTINO, 1994).

Nesse contexto, a iluminação torna-se um fator fundamental, visto que a sua correta aplicação permite que a vivência do espaço noturno assegure a sensação de segurança ao ambiente. Além disso, a abordagem com usuários de espaços de lazer noturnos no estudo de Reckziegel (2009) pontuou a influência da iluminação no destaque de percursos e na intensificação das cores nas fachadas. Segundo o autor, a iluminação também se relaciona diretamente à afloração de diferentes estímulos acerca do espaço. Levando em consideração a atribuição das três variáveis que mais se destacaram nas entrevistas realizadas, incluem-se a facilidade de estacionamento, a percepção de segurança e a iluminação pública.

Compreende-se, portanto, a influência direta entre a iluminação e o ambiente construído, tendo em vista que a:

Iluminação pública é o serviço que tem o objetivo de prover luz ou claridade artificial aos logradouros públicos no período noturno ou nos escurecimentos diurnos ocasionais, incluindo locais que demandem iluminação permanente no período diurno (ROSITO, 2009, p. 32).

Para que a implementação correta de níveis de luminosidade aconteça, é necessário verificar o entendimento do indivíduo sobre o espaço em que ele vive. Para Souza (2017), a percepção do ambiente pode ser explicada a partir da forma, da cor, do tamanho e da luminosidade. Assim, a iluminação se torna eficaz quando, além de despertar percepções acerca do ambiente, garante a funcionalidade do espaço no período noturno (BRAGATTO, 2013). Tendo em vista o impacto que pode resultar do fomento ao desenvolvimento de uma determinada região, a iluminação pública pode auxiliar na captação de recursos por meio da atratividade do comércio e da sensação de segurança (FUHRMANN; MINUSSI, 2014; ALVES; SANTOS, 2016).

Outro atributo que está relacionado à alteração de turno diz respeito à utilização dos mesmos ambientes porém em um contexto diferenciado, o qual tende a despertar as funções motoras e psíquicas do ser humano a partir da iluminação artificial, por exemplo (ROINZEBLATT, 2009). É por isso que a iluminação noturna e a diurna não podem ser comparadas, visto que à noite a iluminação é mais dinâmica por consequência das suas diferenciações de luminosidade e intensidade (AFONSO, HARDT; HARDT, 2011). Assim, a diversificação do espaço por meio da iluminação possibilita a interação com novos usos, transferindo uma maior dinamicidade à vida dos usuários (PIPPI et al., 2003; MOISINHO FILHO, 2008).

A Figura 1 apresenta a construção da ideia perceptiva nos usuários do espaço construído. Os estímulos sensoriais, aliados aos seus

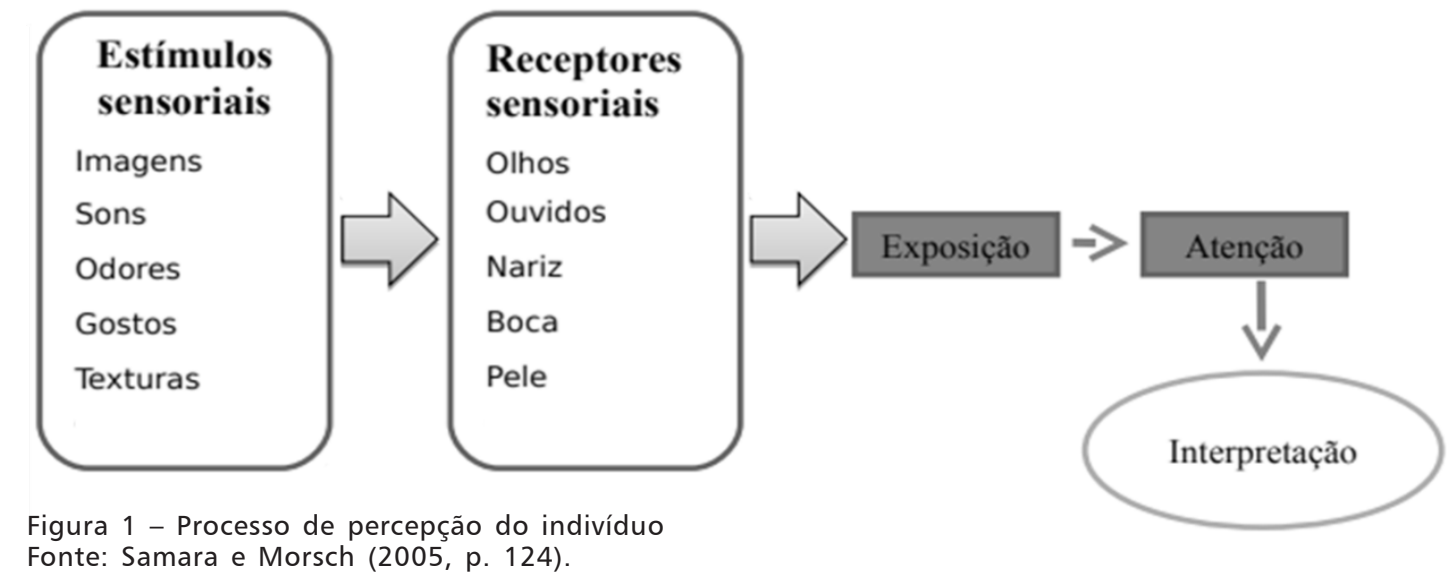


receptores, expõem o indivíduo a uma sensação que gerará uma informação, a fim de transmitir prazer ou desagrado a partir de determinadas situações.

Apesar de focar o seu estudo em locais privados, Semick (2000, apud SAMARA; MORSCH, 2005, p. 123) contribui para a compreensão da percepção do indivíduo frente ao espaço. Segundo a autora, o processo de notoriedade acerca de um local é consequência de fatores culturais e atitudes provindas de comportamentos anteriores, culminando em interpretações pessoais acerca de determinadas situações. Essa diferenciação de percepção a partir de diferentes pontos de vista pode fazer com que um índice mais forte de iluminação em determinado ponto possa ser mais agradável para um indivíduo do que para outro.

Para Lang (1994), o indivíduo se relaciona diretamente com os aspectos naturais e artificiais do ambiente. Para o autor, esses aspectos servem para garantir diferentes finalidades aos que utilizam o espaço. Da mesma forma, Junqueira (2014) encara a iluminação de espaços urbanos com uma arte que é expressada a partir de cenas predefinidas, causando "reações fisiológicas, psicológicas e estéticas no usuário, enquanto arte pública" (JUNQUEIRA, 2014, p. 1).

Essa graduação e diferenciação de cenas luminosas aponta que a paisagem não se resume somente à vivificação do mundo real (natural), mas sim das alterações criadas pelo homem para que as suas necessidades pudessem ser supridas, ou, no caso da iluminação, para que cenas conseguissem ser moldadas conforme os diferentes tipos de intenções (NARBONI, 2004).

Dentre as circunstâncias atuais, encontra-se o direcionamento de iluminação às vias de trânsito veicular. Para Roizenblatt (2009), a compreensão do espaço urbano é resultante de uma percepção de iluminação pública direcionada ao tráfego motorizado. Em outras palavras, entende-se que a projeção de caminhos iluminados aos pedestres acaba sendo a consequência de um tratamento único voltado ao automóvel, ignorando um sistema de tratamento individualizado para os diferentes tipos de mobilidade (ROIZENBLATT, 2009).

Para tanto, torna-se cada vez mais necessário analisar essas questões e propor espaços iluminados para todas as condições de mo- bilidade pública. Enquanto outros mobiliários urbanos cumprem com o papel de garantir conforto e segurança aos indivíduos como bancos e lixeiras -, em muitos momentos eles só conseguem ser perceptíveis ao indivíduo por meio da iluminação dos espaços. Os postes de iluminação, portanto, auxiliam na estruturação da cidade a partir do seu funcionamento, uma das soluções existentes na via pública que transmite conforto e segurança à população (ÁGUAS, 2009).

É importante analisar que essa distribuição da luz em um meio é dada a partir da união de objetos, de um todo que se contrapõe a espaços pontuais iluminados. Arnheim (2000) afirma que:

Várias luzes devem unir-se para uma iluminação uniforme, ou cada uma delas pode criar gradiente de valores de claridade nitidamente autossuficiente. O resultado total pode comunicar ordem visual ou, conforme chamamos anteriormente, harmonia e até mesmo beleza. Iluminação é, portanto, principalmente uma arte, uma arte apoiada pela ciência. Qualquer trabalho baseado apenas na ciência, na tecnologia ou nas recomendações práticas será, no máximo, comum. lluminar requer não somente nossa curiosidade, mas também nossa habilidade em fazer avaliações subjetivas (ARNHEIM, 2000, p. 304).

Desse modo, tão importante quanto a distribuição da iluminação acerca dos trajetos, está a disposição de mobiliários ao logo do percurso, os quais podem cumprir diferentes papéis. Dentre eles, está a sua influência direta na percepção dos usuários em determinados locais (MONTENEGRO, 2005). Para isso, é necessário compreender os diversos entendimentos de mobiliário urbano a partir da visão de diferentes autores que o analisam (Tabela 1).

É com base na gama de elementos públicos estruturados ao longo de ambientes urbanos que se projeta a eficiência da iluminação, com o intuito de esses espaços serem aproveitados com conforto e segurança pelos usuários.

No entanto, é importante pontuar que o excesso de iluminação não a caracteriza como eficiente. Carvalho e Pimenta (2006) afirmam que mais de $30 \%$ da iluminação artificial aplicada em todo o 


\begin{tabular}{l|c|l}
\hline \multicolumn{1}{c|}{ Autores } & Critérios & \multicolumn{1}{c}{ Classificação do mobiliário urbano } \\
\hline ABNT (2014) & Função & $\begin{array}{l}\text { Circulação e transporte, cultura e religião, esporte e lazer, infraestrutura, segurança pública e } \\
\text { proteção, abrigo, comércio, informação e comunicação visual, ornamentação da paisagem e } \\
\text { ambientação urbana. }\end{array}$ \\
\hline MOURTHÉ (1998) & Função & $\begin{array}{l}\text { Elementos decorativos, mobiliário de serviço, mobiliário de lazer, mobiliário de comercializa- } \\
\text { ção, mobiliário de sinalização, mobiliário de publicidade. }\end{array}$ \\
\hline FREITAS (2008) & Função & Descanso e lazer, jogos, barreiras, abrigos, comunicação, limpeza, infraestrutura e paisagismo. \\
\hline KOHLSDORF (1996) & Função e escala & Elementos de informação apostos, pequenas construções, mobiliário urbano. \\
\hline GUEDES (2005) & Função e escala & Elementos de pequeno porte, elementos de médio porte, elementos de grande porte. \\
\hline
\end{tabular}

Tabela 1 - Conceituações de mobiliário urbano

Fonte: John e Reis, 2010. Adaptado pelo autor, 2020

mundo é supérflua, visto que acarreta em um profundo desperdício de energia, gerando um alto custo e danos ao meio ambiente (CARVALHO; PIMENTA, 2006). Além disso, a má distribuição da iluminação pode acarretar condições de baixa iluminância e/ou ofuscamento, como pode ser observado na Figura 2.

É preciso desenvolver um estudo detalhado acerca da luminária a ser utilizada no espaço urbano. Torna-se necessária a inclusão de um senso apurado para perceber as vantagens e desvantagens de sua utilização. Quando se escolhe a lâmpada de vapor de sódio, muito utilizada para a iluminação pública devido à sua coloração amarelada, há uma grande chance de distorção das cores, por outro lado, ela é mais econômica que a luz branca (CARVALHO; PIMENTA, 2006). Além do desconforto visual provocado pela iluminação má distribuída no ambiente, a sensação de insegurança pode aumentar e comprometer a percepção do indivíduo acerca do espaço físico.

\section{A Segurança no Ambiente Noturno}

A poluição luminosa, gerada pela má distribuição da luz no ambiente, pode ser remediada a partir o direcionamento correto da luz no local em que se deseja iluminar. No que tange à segurança do indivíduo, o foco da luz voltado unicamente para baixo, ao invés de iluminar as laterais e a parte superior da fonte de luz, contribui para a economia de energia e para a geração de locais mais iluminados, o que tende a aumentar a sensação de segurança do indivíduo (MARINS, 2019).

Enquanto inicialmente a iluminação esteve vinculada à geração de espaços mais seguros, foi possível observar um avanço no entendimento dos espaços como sendo também noturnos, a fim de buscar novos usuários que os utilizem em diferentes horários do dia (SANTOS, 2014). Para Mier (2013, p. 19), "a iluminação para o pedestre, embora não resolva totalmente o problema da criminalidade é sem dúvida um fator dissuasivo e de prevenção".

É preciso compreender que, além de garantir segurança aos indivíduos, a presença de uma iluminação condizente ao espaço possibilita a prática noturna do comércio, da cultura e do lazer, incitando a vitalidade no meio urbano (CRUZ; SANTOS, 2008).

Atualmente, a violência nas grandes cidades não se trata unicamente de problemas oriundos do crime, mas também de intervenções malsucedidas nos espaços públicos. Segundo Gärtner (2008), a eficácia das gestões urbana e física tende a gerar maior sensação de segurança nos locais, a fim de incorporar estratégias que previnam a 


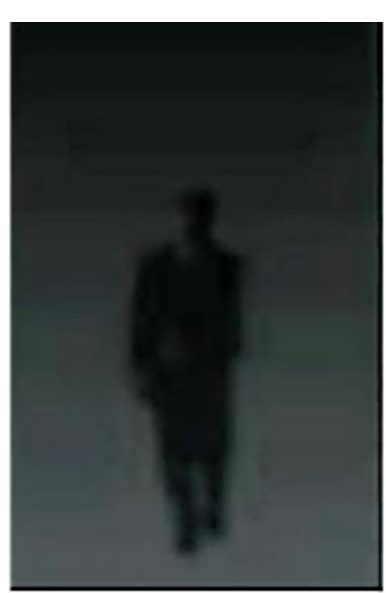

a

Em condições de baixa iluminância o reconhecimento fica prejudicado

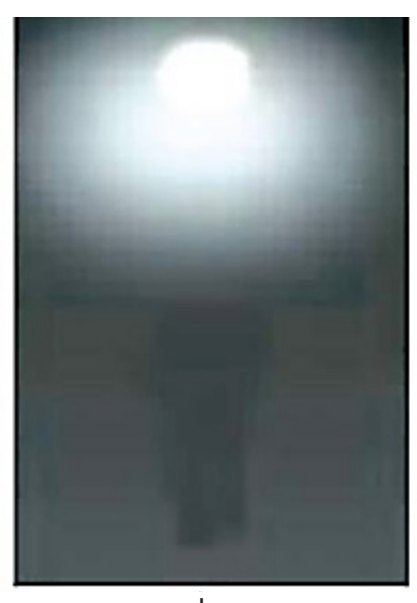

Ofuscamento causado pelas diferenças muito acentuadas na luminância

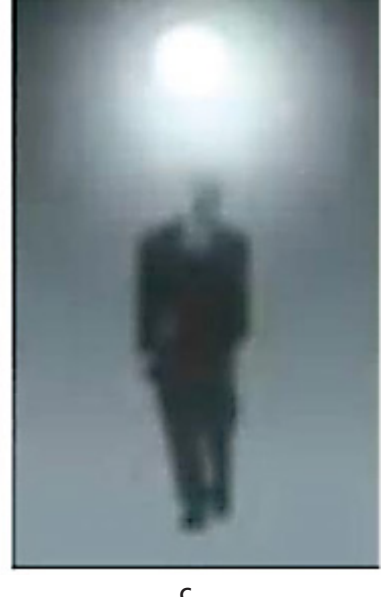

luminância do

ambiente torna objeto visível

Figura 2 - Esquema representativo de diferentes formas de incidência lumínica

Fonte: FGL, 2004. Adaptado pelo autor, 2020

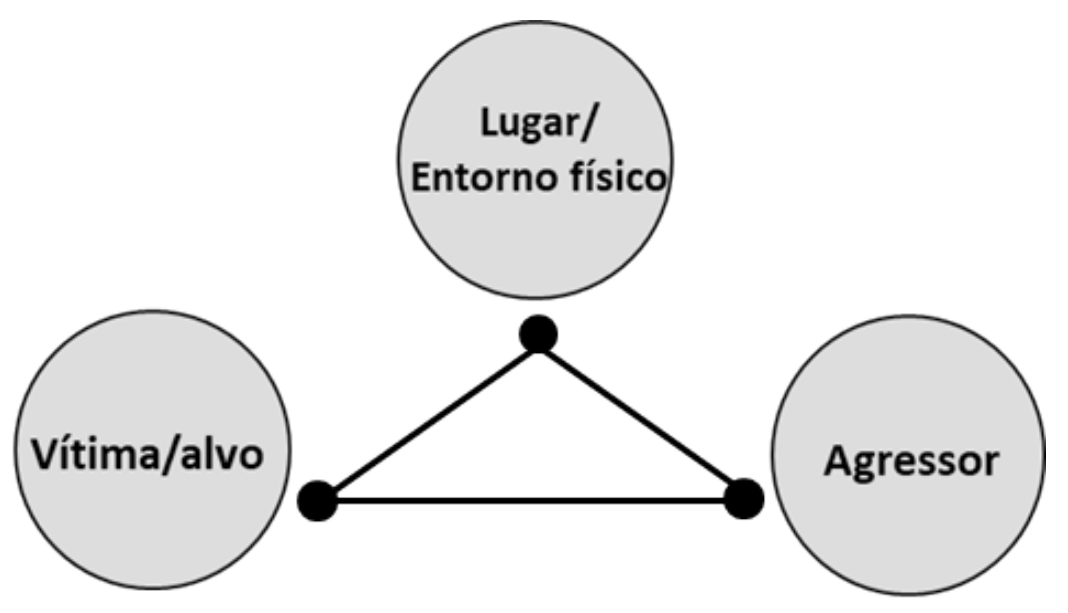

Figura 3 - Relação entre o crime e o espaço vivenciado pelo indivíduo

Fonte: JEFFREY, 1997. Adaptado pelo autor, 2020 
criminalidade. A Figura 3 demonstra o que é usual, a relação de conexão entre a vítima e o agressor no espaço em que estão inseridos.

A orientação de caminhos e a disposição do mobiliário ao longo do percurso são decisões norteadoras para a inibição de suspeitos que possam vir a cometer delitos. Dentre as soluções palpáveis para reduzir as chances de isso ocorrer, resume-se o uso de iluminação adequada junto a artifícios que complementam essa aplicação como a pavimentação e a vegetação, por exemplo (VIEIRA, 2018).

Para Heitor (2007, p. 9), “o ambiente urbano pode influenciar o comportamento fisicamente, proporcionando as condições espaciais onde os indivíduos actuam; socialmente, promovendo as relações sociais a que os indivíduos respondem". Sendo assim, abre-se a discussão acerca do espaço frente ao usuário a fim de compreender a sua permanência ou passagem pelo meio urbano.

Essa investigação de comportamento se relaciona diretamente aos princípios da Prevenção de Crimes por meio de Projetos (CPTED), teoria de prevenção criminal que busca, a partir de seus princípios, o entendimento de uma arquitetura voltada à dinâmica social e às consequências das escolhas projetuais (CARVALHO, 2015). Amaro (2005) também aponta que a construção desse conceito objetiva a diminuição de delitos a partir da inserção de soluções urbanísticas. A Figura 4 sintetiza esses princípios, pontuando seus principais objetivos ao aliar a arquitetura à prevenção da criminalidade.

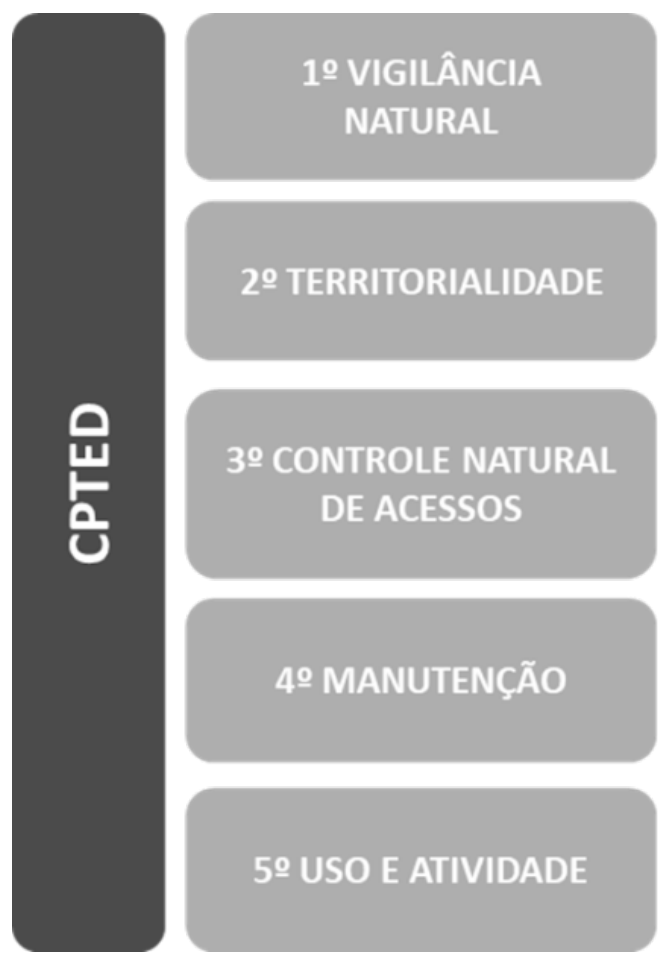

\section{Usuários vigilantes do próprio espaço, através de uma arquitetura e um desenho urbano que permita "ver" e "ser visto."}

Baseia-se no "Defensible Space" delimitando os espaços públicos e privados, auxiliando no aumento do sentimento de pertencimento ao local.

Os caminhos devem ser bem demarcados e visíveis para que o suspeito seja inibido de cometer ações delinquentes.

\section{Baseia-se na teoria "Broken Windows", consistindo em}

manter a qualidade física e funcional de todos os elementos que compõem o espaço público.

Estabelecer usos e inserir atividades no espaço público que permitam a ocupação e aglomeração de pessoas.

Figura 4 - Princípios do CPTED (Prevenção de Crimes por meio de Projetos) Fonte: Vieira, 2018 
Para essa investigação de atributos, inclui-se o princípio da vigilância natural, o qual norteia a necessidade de o ser humano de estar com a sensação de segurança intrínseca em um determinado local. Na prática, essa tranquilidade se dá a partir da inserção de uma iluminação correta, somada à distribuição harmônica de outros fatores, como portas, janelas e árvores, as quais permitem a permeabilidade visual das ações que o cercam (RICARDO; SIQUEIRA; MARQUES, 2013).

Para Souza e Compans (2009), a territorialidade - ou reforço territorial - vem ao encontro da relação do indivíduo com o local em que convive, garantindo um sentimento de pertencimento ao espaço construído. Do mesmo modo, Macarena Rau explicita em sua tese de doutorado a busca por "atividades seguras em áreas seguras", elucidando a necessidade do ser humano de se apropriar do espaço (RAU, 2003).

Outro princípio que também gera uma combinação entre o indivíduo e o meio em que vive é o controle natural de acessos. nitorar o acesso a desconhecidos, estando a par das situações que poderão ocorrer, por exemplo, a partir dos fechamentos nas residências.

Por fim, o princípio da manutenção e uso do espaço está voltado ao olhar dos seus gestores e da população. Quando os espaços públicos não estão bem conservados, a tendência é que o espaço propicie uma maior taxa de criminalidade (BAPTISTA, 2015).

Verifica-se, portanto, a importância de aliar os princípios do CPTED à garantia da vitalidade urbana noturna, a fim de garantir que os usuários se tornem os protagonistas de espaços que possuam a qualidade mínima de conforto e segurança.

Mas para que isso ocorra é necessário conhecer algumas das estratégias existentes para que o local seja repensado a partir de sua humanização e com sensação de segurança. Uma dessas alternativas vai ao encontro dos conceitos estabelecidos por Barbosa (2010). O autor afirma que um local bem iluminado possibilita atrair olhares por meio de focos de atenção, a fim de evidenciar espaços e/ou ob-

jetos, orientando o usuário no espaço. Dentre as funções provindas da luz estão os objetivos de destacar, separar e conectar espaços a partir de hierarquias.

No entanto, em um estudo realizado por Barbieri (2018) voltado à percepção dos idosos na caminhabilidade do ambiente construído, a iluminação noturna pode se tornar ineficaz quando a taxa de criminalidade se sobrepõe à qualidade da distribuição da luz no ambiente. Por mais que a iluminação seja satisfatória em termos técnicos de locação e clareamento nos diferentes pontos, todos esses fatores podem ser entendidos como insuficientes.

Assim sendo, torna-se necessário avaliar espaços públicos no que tange à sua segurança a fim de compreender suas fragilidades e promover possíveis soluções. Para Marques e Galvão (2014), esses estudos possibilitam alertar governantes e a sociedade em geral para o uso do espaço com segurança, com o objetivo de reduzir influências criminais nos momentos de lazer.

\section{Procedimentos Metodológicos}

O presente trabalho visa discutir acerca de diferentes conceitos relacionados à compreensão e aplicações voltadas à iluminação noturna no espaço urbano. Para isso, a pesquisa de revisão sistemática e de análise de estudos de caso incide sobre uma consultoria a livros, periódicos nacionais e internacionais, físicos e digitais, disponíveis em bibliotecas e plataformas virtuais. Dentre elas, inclui-se a busca de informações em plataformas como o Google Acadêmico, Scopus e o Banco de dados de Periódicos CAPES.

Embasado por referências bibliográficas fiéis à temática, obtém-se o comparativo entre espaços urbanos com o atributo da segurança. Verifica-se a relação de estudos de caso resultantes de trabalhos ligados à temática da paisagem urbana e da iluminação pública com os princípios de Prevenção de Crimes por meio de Projetos (CPTED): vigilância natural, territorialidade, controle natural de acessos, manutenção, uso e atividade. 


\section{Resultados e Discussões}

Com base na conceituação apresentada a partir dos princípios de Prevenção de Crimes por meio de Projetos (CPTED), pretende-se compará-los aos espaços públicos relatados abaixo, vislumbrando os fatores que possibilitam ou dificultam a incidência da criminalidade.

Considerado um espaço multifuncional, o Jardim Fernando Pessa, localizado em Lisboa, conta com aproximadamente $14.000,00 \mathrm{~m}^{2}$ e inclui espaços para o lazer e um parque de animais envoltos em áreas arborizadas (VIEIRA, 2018). Nota-se, a partir da Figura 5, a visualização do ambiente a partir da perspectiva de dois horários diferentes. É possível observar a vitalidade representada nos dois turnos, muito provavelmente mantida por meio do mobiliário e da iluminação condizentes com o espaço. Essa relação ambiente-indivíduo pode ser confirmada ao comparar a imagem com os princípios da CPTED, remetendo à vigilância natural possibilitada pela permeabilidade visual consequente das árvores e da inexistência de barreiras físicas. Da mesma forma, a delimitação dos espaços e o controle de acessos são possibilitados por esse permanente monitoramento. Aparentemente, as qualidades física e funcional se mantêm conservadas, permitindo o uso contínuo e a permanência dos indivíduos. Observa-se, também, a distribuição coerente entre postes de iluminação e a luz emitida a partir das lâmpadas existentes.

E essa interação entre o indivíduo e o espaço físico é bastante destacada por Gehl (2014), que defende a necessidade de contato íntimo com o ambiente externo. Segundo o autor, as regras do espaço comum são ditadas pelo interesse público, permitindo que haja relações de cunho pessoal, político e cultural entre os indivíduos. No entanto, é necessário averiguar se os instrumentos determinados pela instituição pública atendem de fato à população.

Para essa análise, apresenta-se, na Figura 6 , um comparativo entre dois tipos de tratamentos de iluminação na Rua 14 de Julho, recentemente revitalizada na cidade de Campo Grande/MS: enquanto um está voltado para a iluminação do pedestre no passeio público, o outro está focado na iluminação da via, o que contribui para uma maior sensação de segurança.
Essa decisão de planejamento urbano que prioriza o pedestre vai na contramão da maioria dos casos brasileiros, em que se privilegia o veículo em detrimento do indivíduo, contrariando a promoção da sociabilidade bastante incrementada no mundo atual, já que a iluminação elétrica evoluiu de tal forma que possibilitou o convívio noturno a partir da gama de conteúdos espaciais de diferentes tipos, como passeios públicos, praças e bares (GWIAZDZINSKI, 2005).

Mesmo que o tráfego de veículos e pedestres seja de grande fluxo em diferentes pontos das cidades, a iluminação em áreas periféricas ainda é bastante precária. Como consequência, tornam-se áreas mais escuras em relação às centrais, o que culmina em um fator segregante (ROIZENBLATT, 2009).

Essas distinções podem ser consequência da segregação espacial em meio à cidade. Enquanto os grandes centros são mais iluminados devido à presença de áreas comerciais, os bairros mais afastados tendem a ser desassistidos pelo poder público (MOREIRA JÚNIOR, 2010). Segundo Marcuse (2004), esse distanciamento é consequência da divisão funcional decorrente da lógica econômica, determinada a partir de atividades adversas no meio urbano.

A inexistência de postes de iluminação de qualidade ao longo de uma via, utilizando o poste exclusivamente como passagem de fiações, pode colocar risco aos moradores. Ainda, a falta de passeios públicos estruturados sob a perspectiva de escuridão tende a promover um espaço perigoso devido à geração de sensação de insegurança e acidentes que possam vir a ocorrer por consequência da falta de visibilidade ao longo do percurso.

Assim, essas irregularidades vão contra os princípios da CPTED, visto que não dispõem de um projeto funcional que favoreça a população local para que a mesma se sinta segura no espaço em que vive. A ideia do "ver e ser visto" (VIEIRA, 2018) é completamente ignorada pelos poderes controladores da esfera pública, escanteando as necessidades de manutenção dos espaços de uso comum e descumprindo com o princípio de territorialidade, em que o morador se sente pertencente ao meio urbano público. 


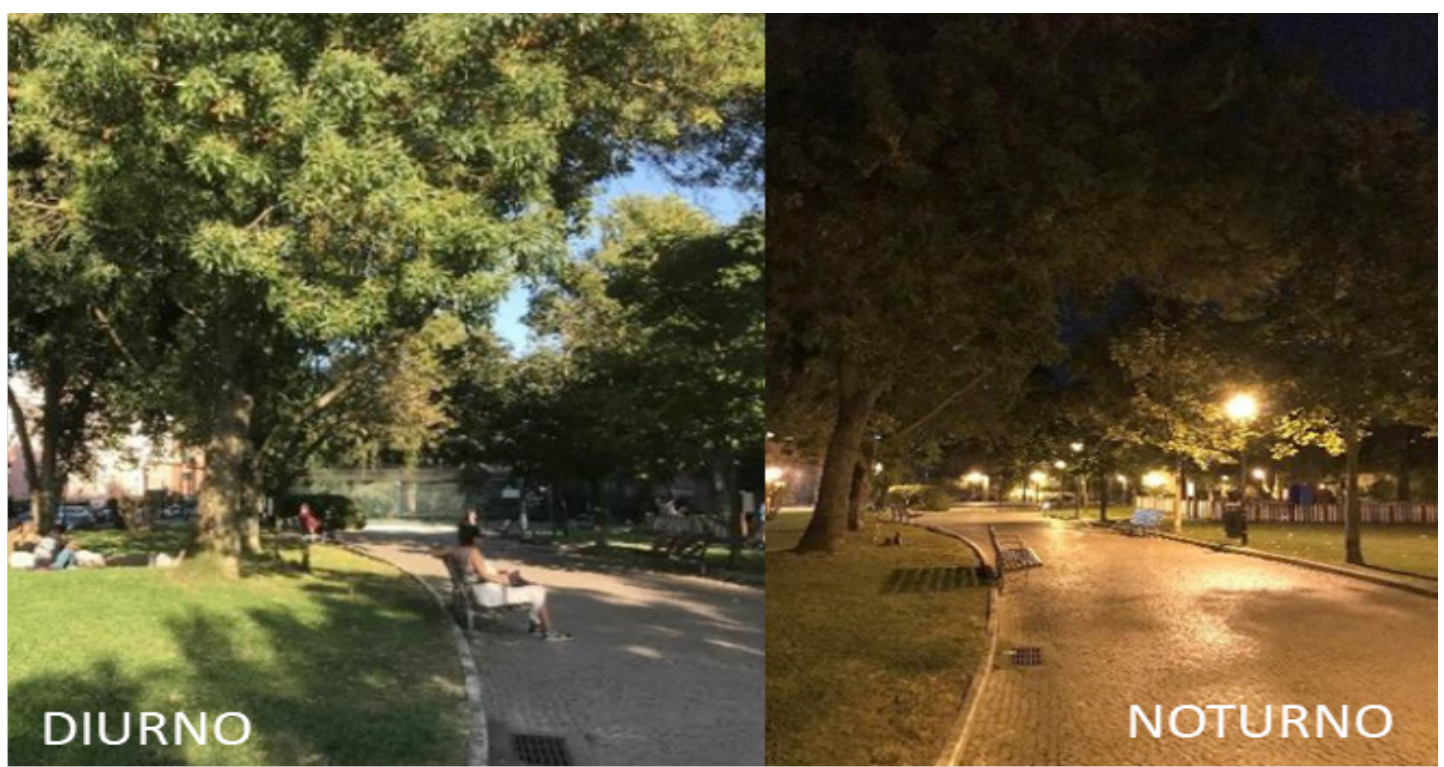

Figura 5 - Cenas de um parque em horários diurno e noturno, respectivamente

Fonte: Vieira, 2018. Adaptado pelo autor, 2020
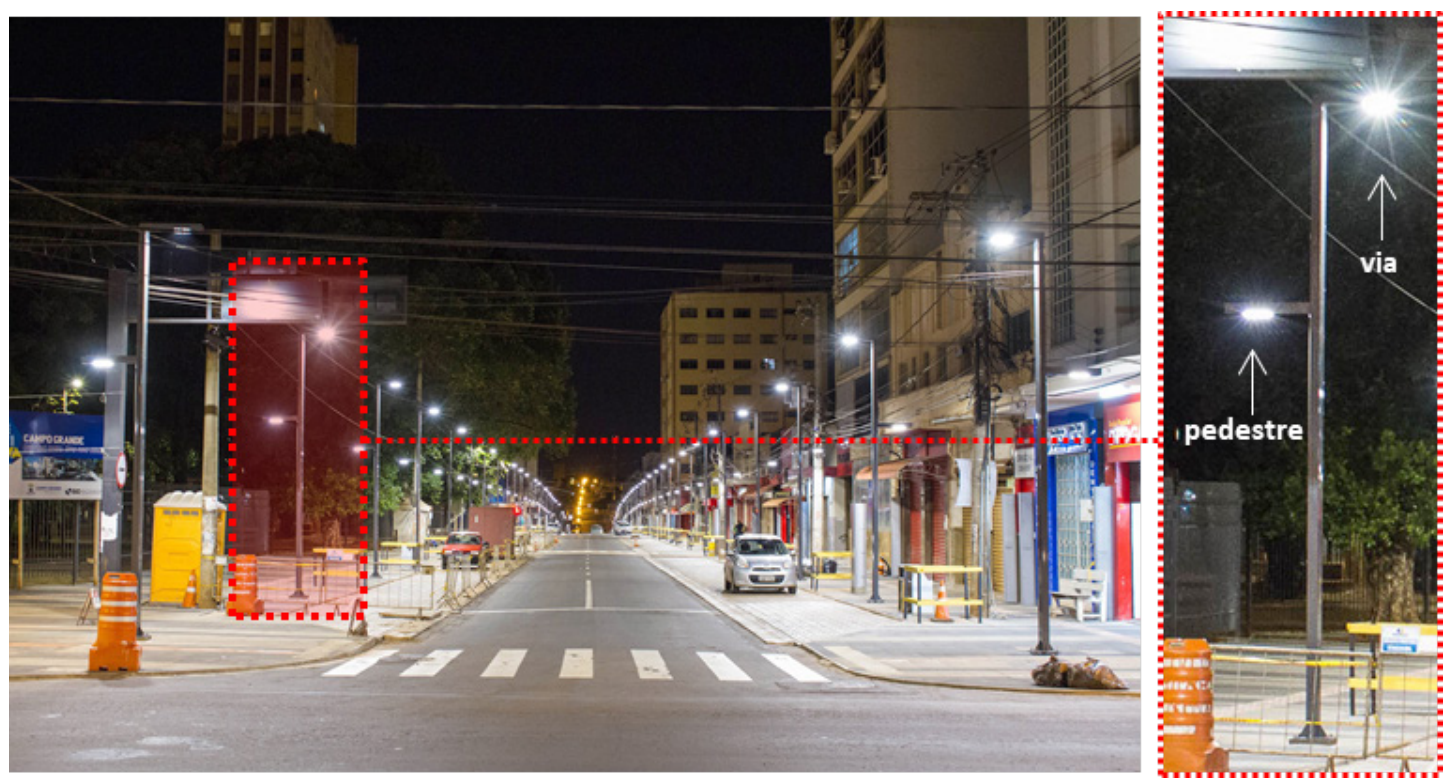

Figura 6 - lluminação pública voltada ao pedestre e à via na Rua 14 de Julho em Campo Grande/MS

Fonte: Prefeitura de Campo Grande, 2019.

Adaptado pelo autor, 2020. 


\section{Conclusão}

Após uma breve compreensão da importância da iluminação noturna no espaço urbano, pôde-se compreender a sua importância junto à vitalidade urbana, a qual norteia a aglomeração de pessoas a partir de diferentes atividades. Foi necessário pensar sobre a responsabilidade pública de espaços de uso comum e a relação com a participação da população a partir de avaliações acerca do ambiente construído. Assim, observou-se que o entendimento de princípios que norteiam o uso e a apropriação dos espaços livres se torna ainda mais concreto, a fim de fortalecer o uso e apropriação públicos a partir da inexistência da sensação de insegurança predominante em locais ineficientes.

A partir de estudos sobre diferentes conceitos ligados à compreensão e aplicações voltadas à iluminação noturna no espaço urbano, avaliaram-se estudos de casos de iluminação pública satisfatória e insatisfatória, relacionando-os com os princípios de Prevenção de Crimes por meio de Projetos (CPTED): vigilância natural, territorialidade, controle natural de acessos, manutenção, uso e atividade. Pôde-se observar pontos positivos e negativos dos casos apresentados em relação à sensação de segurança e/ou insegurança noturna.

Dentre as discussões, incluiu-se fortemente a relação do espaço urbano com o princípio de vigilância natural, exacerbado positivamente em áreas centrais e negligenciado em bairros adjacentes, devido à falta de locais iluminados. Em um sentido mais amplo, verificou-se a necessidade de se pensar o espaço urbano a partir de um planejamento consistente, excetuando-se diferenças espaciais de solo urbano e focando em medidas que transfiram benefícios diretos à população.

\section{RefERÊNCIAS BIBLIOGRÁficAs}

ABNT. Associação Brasileira de Normas Técnicas. NBR 9283: Mobiliário Urbano. Rio de Janeiro, 2014.

AFONSO Taís Maros; HARDT, Letícia Peret Antunes; HARDT, Carlos. Paisagem iluminada: avaliação de cenários urbanos noturnos na região central de Curitiba, PR. Revista Sodebras, v.6, n.72, dez. 2011. p. 3-8.
ÁGUAS, Sofia Isabel Ressano Garcia Vasques Seabra. Design de candeeiros de iluminação pública para a sustentabilidade do espaço público. 2009. 525 f. Tese (Doutorado) - Curso de Faculdade de Bellas Artes, Universidade de Barcelona, Barcelona, 2009.

ALVES, Diana Felipe; SANTOS, Adriane Shibata. A iluminação pública e sua função nos centros urbanos. Gampi Plural, São Paulo, v. 2, n. 41 ,

p. 1-17, 2016

AMARO, Marcos Antonio. Arquitetua contra o crime: PCAAA - prevenção do crime através da arquitetura ambiental. Rio de Janeiro: Marcos Antonio Amaro, 2005.

ARNHEIM, Rudolf. Arte e percepção visual: uma psicologia da visão criadora / Rudolf Arnheim; tradução Ivone Terezinha de Faria. 13. ed. São Paulo: Pioneira, 2000

BAPTISTA, João José Modesto. A Segurança no desenho urbano: uma abordagem CPTED. 2015. 94 f. TCC (Graduação) - Curso de Relatório Científico Final do Trabalho de Investigação Aplicada, Academia Militar, Lisboa, 2015.

BARBIERI, Amanda Renata. Envelhecimento e urbanização: a percepção dos idosos na "caminhabilidade" e a qualidade de vida no ambiente construído em Ttajubá - MG. 2018. 61 f. Dissertação (Mestrado) - Curso de Mestrado em Meio Ambiente e Recursos Hídricos, Universidade Federal de Itajubá, Itajubá, 2018.

BARBOSA, Cláudia Verônica Torres. Percepção da iluminação no espaço da arquitetura: preferências humanas em ambientes de trabalho. 2010. 251 arquitetura: preferências humanas em ambientes de trabalho. 2010. 251 f. Tese (Doutorado) - Curso de Programa de Pós-graduação em Ar São Paulo, 2010

BARGOS, Danúbia Caporusso; MATIAS, Lindon Fonseca. Áreas verdes urbanas: um estudo de revisão e proposta conceitual. Revsbau, Piracicaba, v. 6, n. 3, p. $172-188,2011$

BRAGATTO, Nathália Ceccato. Importância da iluminação nos bares e restaurantes e sua influência no comportamento dos usuários. Especialize, Goiânia, p. 1-17, 2013.

CARVALHO, Ana Catarina. A Segurança Urbana e o Desenho do Espaço Público: contributos para a prevenção do crime e de incivilidades. 2015. 190 f. Dissertação (Mestrado) - Curso de Mestrado em Ciências Policiais, Instituto Superior de Ciências Policiais e Segurança Interna, Lisboa, 2015.

CARVALHO, Carlos; PIMENTA, Jose Luiz. Iluminação pública e o uso eficiente das fontes de luz. Lume Arquitetura, p. 24-29, maio 2006.

CONSTANTINO, Núncia Santoro de. A conquista do tempo noturno: Porto Alegre "moderna". Estudos Ibero-americanos, Porto Alegre, p. 65-84, dez. 1994.

CRUZ, lamara Ayres Silva da; SANTOS, Evandro. Recuperação de área central com base no aumento do índice de caminhabilidade, na aplicação dos conceitos de acessibilidade universal e na arquitetura aplicação dos conceitos de acessibilidade universal e na arquitetura
inclusiva em Curitiba. Da Vinci, Curitiba, v.5, n. 1, p. $21-49,2008$. inclusiva em Curitiba. Da Vinci, Curitiba, v.5, n. 1, p. $21-49,2008$.
Disponível em: http://www.up.edu.br/davinci/5/pdf16.pdf. Acesso em: 10 abr. 2020. 
FERNANDES, Samuel Roda. "Paisagens lumínicas e transfiguração da noite em Sintra - o Aura Festival. In: FREIRE, Patrícia. A Cidade Não Adormece. [s. L.]: Espaço Cpi, 2016. p. 8-9.

FGL - FORDERGEMEUNSCHAFT GUTES LICHT. Good lighting for safety on roads, paths and squares. Braunschweig, Westermann Druck, 2004.

FREITAS, Ruskin Marinho de. Mobiliário Urbano. In: MASCARO, Juan Luís (org.) FUHRMANN, Marcelo Weber; MINUSSI, João Paulo. A eficiência da iluminação pública como ferramenta de gestão - estudo de caso. 2014 $17 \mathrm{f}$. Monografia (Especialização) - Curso de Curso de Pós-graduação em Eficiência Energética Aplicada Aos Processos Produtivos, Universidade Federal de Santa Maria, Panambi, 2014.

GÄRTNER, Anika. Desenho do espaço público como ferramenta para a prevenção da violência. Revista Brasileira de Segurança Pública, São Paulo, p. 56-67, 2008.

GEHL, Jan. Cidades para pessoas. 2. ed. São Paulo: Perspectiva, 2014. 280 p. GÓIS, Marcos Paulo Ferreira de. Luzes na Cidade: sobre as Paisagens Luminosas e os Cenários Noturnos da Cidade do Rio de Janeiro. Espaço Aberto, Rio de Janeiro, v. 1, n. 2, p. 117-127, 2011

GUEDES, João Batista. Design no Urbano: Metodologia de Análise Visual de Equipamentos no Meio Urbano. Tese (Doutorado em Desenvolvimento Urbano, Universidade Federal de Pernambuco, 2005). Disponível em: < http:// www.bdtd.ufpe.br/>. Acesso em: 05 maio 2020

Les Annales de la Recherche Urbaine, n.87, 2000, p. 81-8.

HEITOR, Teresa. Insegurança em meio urbano: o espaço na medição de oportunidades delituosas. Revista Psicologia, v. XXI, n. 2, p. 31-44, 2007 Infraestrutura da Paisagem. Porto Alegre: Mais Quatro, 2008.

JACOBS, Jane. Morte e vida das grandes cidades. São Paulo: Martins Fontes, 2000.

JEFFREY, C. Ray. Crime Prevention through Environmental Design. 2 ed. Beverly Hills, Sage, 1997.

JOHN, Naiana; REIS, Antonio Tarcísio da Luz. Percepção, estética e uso do mobiliário urbano. Gestão \& Tecnologia de Projetos, São Carlos, v. 5, n. 2 p. 180-206, nov. 2010.

JUNQUEIRA, Mariana Garcia. A vocação expressional da luz: o design da luminação no espaço urbano contemporâneo como arte pública. Revista Ciclos, Florianópolis, v. 1, n. 2, p. 1-15, fev. 2014

KOHLSDORF, Maria Elaine. A apreensão da Forma da Cidade. Brasília: Editora Universidade de Brasília, 1996.

LANG, Jon. Urban Design: the american experience. New York: Van Nostrand Reinhold, 1994.

MARCUSE, Peter. Enclaves, sim; guetos, não: a segregação e o estado. In: Espaço e Debates. São Paulo: NERU. v. 24, n. 45, p. 24 - 33, jan./jul. 2004.

MARINS, Daniela Pawelski Amaro; VALE, Claudia Camara; SILVA, Malena Ramos; ALVAREZ, Cristina Engel de. Poluição luminosa: compilação de estudos científicos que comprovam que a luz excessiva das cidades interfere nos seres vivos. In: XVIII SBGFA - SIMPOSIO BRASILEIRO DE GEOGRAFIA FISICA APLICADA, 18., 2019, Fortaleza. Anais [...]. Fortaleza: Universidade Federal do Ceará, 2019. p. 1-12.

MARQUES, Eduardo Garcia da Costa; GALVÃO, Fernando Cezar Lisik. O combate a criminalidade em Dourados/MS através da cooperação entre a secretaria municipal de serviços urbanos e a polícia militar. 2014. $12 \mathrm{f}$ TCC (Graduação) - Curso de Mestrado Profissional em Administração Pública, Profiap, 2014.

MASCARÓ, Lucia. A iluminação do espaço público. Arqtexto, Porto Alegre, p. 20-27, 2006

MIER, Rita. Por uma estrutura luminosa sustentável no território paulista: uma análise ao longo da estrada dos romeiros. Revista LABVERDE, São Paulo, n.7, 2013, p.13-37.

MOISINHO FILHO, Elso de Freitas. Patrimônio cultural e iluminação urbana em São Cristóvão - SE. NUTAU/USP- $7^{\circ}$ Seminário Internacional Espaço Sustentável: Inovações em Edifícios e Cidades. Art. 157. São Paulo, abril de 2008. Disponível em: http://www.usp.br/nutau/CD/157.pdf Acesso em: 02 abr. 2019.

MONTENEGRO, Glielson. A produção do mobiliário urbano em espaços públicos: o desenho do mobiliário urbano nos projetos de reordenamento das orlas do RN. Dissertação (Mestrado em Arquitetura e Urbanismo, Universidade Federal do Rio Grande do Norte, Natal, 2005). Disponível em: <http://bdtd.ibict.br/> Acesso em 10 maio 2019.

MOREIRA JÚNIOR, Orlando. Cidade partida: segregação induzida e autosegregação urbana. Caminhos de Geografia, Uberlândia, p. 1-10, 2010

MOSER, Gabriel. Psicologia Ambiental. Estudos de Psicologia, Natal, v. 3, n. 1, p. 121-130, 1998

MOURTHÉ, Cláudia. Mobiliário Urbano. Rio de Janeiro: 2AB, 1998.

NARBONI, Roger. Lighting the landscape - art, design, technologies. Switzerland: Birkhauser, 2004.

PIPPI, Luis Guilherme Aita; AFONSO, Sonia; SANTIAGO, Alina. A aplicação da sustentabilidade no ambiente urbano. In: III ENECS - Encontro Nacional sobre edificações e comunidades sustentáveis, 2003. Brasília: III ENECS, 2003. Disponível em: soniaa.arq.prof.ufsc.br/sonia/ENECS/guilherme2003.pdf Acesso em: 05 abr. 2019.

PREFEITURA DE CAMPO GRANDE. Reviva Campo Grande entra em contagem regressiva para ser entregue à população. 2019. Disponível em: http://www.campogrande.ms.gov.br/cgnoticias/galerias/reviva-campogrande-entra-em-contagem-regressiva-para-ser-entregue-a-populacao/. Acesso em: 20 mar. 2020.

RAU, Macarena. Prevención de la Delincuencia. Prevención de la Delincuencia Mediante el Diseño Ambiental, 2003

RECKZIEGEL, Daniela. Lazer noturno: aspectos configuracionais e formais e sua relação com a satisfação e preferência dos usuários. 2009. 218 f. Dissertação (Mestrado) - Curso de Programa de Pós-graduação em 
Planejamento Urbano e Regional - PROPUR, Faculdade de Arquitetura, Universidade Federal do Rio Grande do Sul, Porto Alegre, 2009.

RIBEIRO, Flávia Alice Borges Soares. Arborização urbana em Uberlândia: percepção da população. Revista da Católica, Uberlândia, v. 1, n. 1, p. 224 237, 2009.

RICARDO, Carolina de Mattos; SIQUEIRA, Paloma Padilha de; MARQUES, Cristina Redivo. Estudo conceitual sobre os espaços urbanos seguros. Revista Brasileira de Segurança Pública, São Paulo, v. 7, n. 1, p. 200-216, mar. 2013

ROIZENBLATT, Isac. Critérios da iluminação elétrica urbana. 2009. $196 \mathrm{f}$. Tese (Doutorado em Arquitetura e Urbanismo). Programa de Pós-Graduação em Arquitetura e Urbanismo da Universidade Presbiteriana Mackenzie, São Paulo, 2009

ROSITO, Luciano Haas. Desenvolvimento da iluminação pública no Brasil. O Setor Elétrico, São Paulo, SP, p. 1-57, jan. 2009.

SAMARA, Beatriz Santos; MORSCH, Marco Aurélio. Comportamento do consumidor: conceitos e casos. São Paulo: Prentice Hall, 2005.

\section{SANTOS, Lúcia Fernandes. Ensaio de método de análise integrada das} condições de iluminação diurna e noturna em praças: avaliação de dois estudos de caso. 2014. 148 f. Dissertação (Mestrado) - Curso de Programa de Pós-Graduação em Arquitetura e Urbanismo, Centro Tecnológico,

Universidade Federal de Santa Catarina, Florianópolis, 2014.

SANTOS, Milton. Metamorfoses do espaço habitado. São Paulo: Edusp, 2008.

SIQUEIRA, Marcos Tadeu Boldrin. Arquitetura e prevenção do crime: análise da relação entre crime e edificações na cidade de Marília/ SP. Revista do Laboratório de Estudos da Violência da Unesp/marília, Marília, p. 132-154, maio 2013

SOUZA, Camila Dias de. A percepção da qualidade do sistema de iluminação artificial da praça Adair Figueiredo. 2017. 188 f. Dissertação (Mestrado) - Curso de Programa de Pesquisa e Pós-graduação em

Arquitetura - PROPAR, Faculdade de Arquitetura, Universidade Federal do Rio Grande do Sul, Porto Alegre, 2017.

SOUZA, Maria Julieta Nunes de; COMPANS, Rose. Espaços urbanos seguros: A temática da segurança no desenho da cidade. Revista Brasileira de Estudos Urbanos e Regionais, São Paulo, v. 11, n. 1, p. 9-24, 2009.

VIEIRA, Amanda Monteiro. 0 desenho urbano como estratégia no incremento da percepção de segurança no espaço público. 2018. $88 \mathrm{f}$. Dissertação (Mestrado) - Curso de Mestrado em Urbanismo Sustentável e Ordenamento do Território, Universidade Nova de Lisboa, Lisboa, 2018.
Felipe Buller Bertuzzi

Universidade Católica Dom Bosco

Av. Tamandaré, 6000 - Jardim Seminario, Campo Grande - MS, Brasil https://orcid.org/0000-0003-0539-606X

arq.felipebertuzzi@gmail.com

Nota do editor:

Data de submissão: 21/09/2020

Aceite: 21/07/2021

Revisão: 